\title{
Forecasting ocean warming impacts on seabird demography: a case study on the European storm petrel
}

\author{
Cecilia Soldatini ${ }^{1}$, Yuri Vladimir Albores-Barajas ${ }^{1, *}$, Bruno Massa $^{2}$, \\ Olivier Gimenez ${ }^{3}$
}

${ }^{1}$ Unidad La Paz, Centro de Investigación Científica y de Educación Superior de Ensenada, La Paz, Baja California Sur, 23050, Mexico

${ }^{2}$ Department of Agriculture and Forest Sciences, University of Palermo, Viale Scienze 13, 90128 Palermo, Italy

${ }^{3}$ CEFE UMR 5175, CNRS, Université de Montpellier, Université Paul-Valéry Montpellier, EPHE, 1919 Route de Mende, 34293 Montpellier Cedex 5, France

\begin{abstract}
Bottom-up climatic forcing has been shown to be influential for a variety of marine taxa, but evidence on seabird populations is scarce. Seasonal variation in environmental conditions can have an indirect effect on subsequent reproduction, which, given the longevity and single-brooding of seabirds, may affect population dynamics. Our study focuses on linking the effect of oceanographic conditions (from 1991 to 2013) to the fecundity and consequently population growth rate of the Mediterranean subspecies of the European storm petrel Hydrobates pelagicus melitensis. In this study, we examined $23 \mathrm{yr}$ of $>5400$ capture-mark-recaptures (CMR) and modelled the probability of skipping reproduction as a function of oceanographic variables using CMR models. We demonstrate that a decrease in sea surface temperature in the pre-breeding period negatively influences skipping propensity, and therefore hypothesize that this behaviour would have significant influence on population abundance over time. For this reason, we analysed population growth as a function of skipping probability as affected by oceanographic conditions. We used stochastic demographic models to forecast the fate of the population, and evaluated contrasted environmental condition scenarios. As a result, we found that a decrease in frequency of cold winter events would probably reduce skipping propensity, with a positive effect on the population as a whole.
\end{abstract}

KEY WORDS: Capture-mark-recapture - Environmental stochasticity $\cdot$ Hydrobates pelagicus · Population growth rate $\cdot$ Senescence

\section{INTRODUCTION}

\section{Seabirds and environmental variability}

Understanding species' sensitivity to environmental change is essential for assessing their present status and predicting future trends -2 key elements of conservation. Birds are a well-studied group, and many studies have reported the impacts of climate and environmental conditions on their life histories (for reviews see Walther et al. 2002, Parmesan 2006, Grémillet \& Boulinier 2009, Jenouvrier 2013, Chambers et al. 2015). Climate change may affect birds at different scales, for example by causing changes in their distribution, phenology, population dynamics and demographic traits. Together with habitat loss, pollution, and introduced predators and/or competitors, climate change is considered the major threat to the persistence of many avian populations (Møller et al. 2004, Halpern et al. 2007, Hoegh-Guldberg \& 
Bruno 2010, Maxwell et al. 2013). In this context, adaptation, phenotypic plasticity, and homeostasis are essential defences against extinction (Møller et al. 2008) and may contribute to population robustness in response to climate change (Jenouvrier 2013), i.e. the species' ability to cope with climate change. However, assessing robustness to climate change is challenging due to the many factors involved.

Seabird species have evolved in oceanic systems characterized by cyclic climatic events, but are negatively affected by the rapid increase of environmental stochasticity resulting from global warming, which can induce a temporal mismatch between life history strategies and increasingly erratic environmental oscillations (Jenouvrier et al. 2008, Ainley et al. 2010, Barbraud et al. 2011, Sydeman et al. 2012). However, the effects of extreme climatic events are far from being understood; some cases remain unexplained and results of studies are contradictory (Croxall et al. 2002, Forcada \& Trathan 2009, Jenouvrier et al. 2015, Bailey \& van de Pol 2016). Breeding performance in particular may be affected directly by sea surface temperature (SST) by changing the distribution and/or abundance of important prey species (Frederiksen et al. 2007), or indirectly via effects on prey recruitment (Hedd et al. 2006). Furthermore, unfavourable climate conditions may induce seabirds to skip breeding (Jenouvrier et al. 2005a, Olivier et al. 2005, Cubaynes et al. 2011) or affect nest-site conditions (Chambers et al. 2011, Moreno \& Møller 2011, Soldatini et al. 2014).

\section{Global climatic oscillations and environmental variability in the Mediterranean}

The North Atlantic Oscillation index (NAO) and the Atlantic Multidecadal Oscillation are decadal climate indices with strong influences on ocean and terrestrial ecosystems in North America and Europe. These indices modulate a variety of phenomena such as precipitation, surface winds, and upwelling, thus influencing ecosystem states at a macro-scale (from hundreds to thousands of kilometres) (Stommel 1963, Nye et al. 2014). On a meso-scale (from tens to hundreds of kilometres), upwelling in the Mediterranean is driven by current systems and prevailing winds (Agostini \& Bakun 2002). Upwelling conditions enhance nutrient circulation and positively affect primary producers, which in turn has a direct effect on subsequent trophic levels, thereby enhancing the trophic web. These conditions support predator populations (Agostini \& Bakun 2002, Reul et al.
2005, Coll et al. 2006, Baum \& Worm 2009). Overall, the presence of an upwelling area in the proximity of seabird colonies has positive effects on the population.

In the Mediterranean, future temperatures are predicted to increase and rainfall to decrease (Bladé et al. 2012). These changes could positively affect nesting seabirds by allowing higher fledging survival (Soldatini et al. 2014). On the other hand, a generalized rise in temperature could affect the entire marine food web, with unpredictable consequences for seabird population trends (Paleczny et al. 2015).

\section{The intermittent breeding strategy}

Due to the high costs of reproduction, seabirds often skip reproduction as an adaptive strategy in response to environmental constraints that favours their own survival and future reproduction (Jenouvrier et al. 2005b, Giudici et al. 2010, Cubaynes et al. 2011, Reed et al. 2015). Intermittent breeding is actually a widely observed phenomenon, which can be modelled based on the cost of reproduction (Shaw \& Levin 2013). It is found not only in seabirds but also, notably, in reptiles and fishes (Tinkle 1962, Thorpe 1994, Solow et al. 2002) which incur lower energetic costs related to reproduction than birds. Breeding success tends to follow ecosystem productivity. At the individual level, the cost of intermittent breeding corresponds more to a breeding season without reproductive output than to a loss, while at a population level it may result in a temporary loss from a demographic point of view (Jenouvrier et al. 2005b). On the other hand it may result in enhancement of future breeding probabilities, as postulated by the prudent-parent hypothesis (Le Bohec et al. 2008).

Pre-breeding climatic conditions strongly affect recruitment age (Soldatini et al. 2014). Here we extend this research by investigating oceanographic effects on skipping propensity, with the expectation that this phenemenon is more frequent in unfavourable environmental conditions (Cubaynes et al. 2011). Intermittent breeding was found to be associated with a range of factors, including the availability of food resources, in mammals (Pilastro et al. 2003) and birds (Newton 1995, 1998). In some seabird species, including gulls (Calladine \& Harris 1997, Mills et al. 2008), kittiwakes (Cam et al. 1998), penguins (Jiguet \& Jouventin 1999) and petrels (Barbraud \& Weimerskirch 2005), intermittent breeding is described in association with environmental constraints or, in the case of shearwaters (Sanz-Aguilar 
et al. 2011), as a characteristic of individuals with a lower intrinsic quality. Furthermore, reproduction skipping was described as a consequence of incomplete primary moult in albatross (Langston \& Rohwer 1996).

\section{Research approach and hypotheses}

Our study focuses on tracing the effect of oceanographic conditions on the demography of the Mediterranean subspecies of the European storm petrel Hydrobates pelagicus melitensis ('storm petrel' hereafter). Most of the known colonies of this subspecies (Mante \& Debize 2012) are located close to continental slopes, with larger colonies closer $(5-6 \mathrm{~km}$ for Marettimo, the colony investigated in this study, and Filfla, the other major colony known for the species) than smaller colonies (found at a distance of between 20 and $40 \mathrm{~km}$ ), and all are in areas where up-welling occurs (Agostini \& Bakun 2002, Massetti 2004). Wintering storm petrels are thought to move to the Alboran Sea (Soldatini et al. 2014), a particularly nutrientrich area that benefits from currents inflowing from the Atlantic Ocean (Agostini \& Bakun 2002, Reul et al. 2005, Renault et al. 2012).

This is a first attempt at a deeper analysis of the demography of the Mediterranean storm petrel, considering population growth as a function of oceanographic conditions (Van Houtan \& Halley 2011). Some demographic traits of the storm petrel were described in previous studies (Sanz-Aguilar et al. 2008, 2009, Soldatini et al. 2014), but information on senescence and age effects on the species' demography is still lacking. In particular, the differential responses of age classes to environmental constraints shape survival and reproductive traits at a population level and probably influence the response of populations to global climate change (Pardo et al. 2013). As a consequence, in order to understand the influence of future climate on this and other seabird species, an assessment on how climate is currently related to population metrics is needed (McClure et al. 2013). These results can then be projected onto a possible future scenario in order to model demographic responses to anticipated climate-related changes, the magnitude of which is not yet recorded in human history (McClure et al. 2013). We are thus modelling demographic traits and their variability in response to environmental constraints.

Our hypothesis was that changes in population growth rates are due to variation in skipping frequencies as a consequence of periodically oscillating climatic conditions. We expected to find a decrease in population growth rate in cases where there is an increase in the frequency or magnitude of cold anomalies in SST. A similar approach was applied to loggerhead sea turtles (Van Houtan \& Halley 2011), a similarly long-lived species whose recent decline appears to be the result of climatic changes, and for which further significant declines are predicted in coming decades, according to available climatic data. Using more than 20 years of capture-markrecapture (CMR) data and >5400 marked individuals, our aim was to investigate the effects of climate change on this seabird species.

\section{MATERIALS AND METHODS}

\section{Study area and species}

CMR data were obtained from the capture and banding of storm petrel chicks and adults on Marettimo Island, located in the Sicilian Channel, Italy $\left(37^{\circ} 58^{\prime} \mathrm{N}, 12^{\circ} 03^{\prime} \mathrm{E}\right)$, between 1991 and 2013. Fieldwork was carried out by certified ringers authorized by the Institute for Research and Environmental Protection (ISPRA) to handle adults and chicks. The main colony on the island consists of approximately 2500 pairs (Albores-Barajas et al. 2012). Each year, the colony was visited at least once between June and August, and adults and chicks were banded with stainless steel rings, resulting in a total of 5168 marked individuals (ringing and recapture data available upon request from the ringing unit of the University of Palermo, www.ornitologiasiciliana.it/contatti. $\mathrm{htm})$. Once fledged in September-October, chicks are not observed at the colony until their first breeding attempt that usually occurs 1 to 6 yr after fledging. Recruitment age is negatively affected by cold conditions in the pre-breeding season (Soldatini et al. 2014). Following breeding, adults depart from the colony. Yearling survival is estimated to be $\sim 22 \%$ and is strongly affected by first year climatic conditions. The survival of juveniles (pre-breeders, 2 to $3 \mathrm{yr}$ old) is also affected by climatic conditions and estimated to be $\sim 50 \%$. The estimated survival of breeders is $\sim 92 \%$ (Soldatini et al. 2014). Fieldwork was carried out under permit nos. 1625/2013, 1721/ 2012, 3/2011 and unnumbered permits before 2011 from the Marine Protected Area 'Isole Egadi'. No ethics committee approval requirements were necessary due to the minimum handling of the individuals under Italian and Sicilian regional legislation (LN 157/92, LR 105/99 and LR 74/2012). 
Table 1. Results of goodness-of-fit tests for the multistate capture-mark-recapture model. The model was tested for transience (Test 3G) and for trap dependence (Test M)

\begin{tabular}{|lccc|}
\hline Test component & $\chi^{2}$ & df & $p$ \\
\hline Global test & 116.576 & 55 & $<0.0001$ \\
Test 3G & 104.242 & 37 & $<0.001$ \\
Test M & 12.334 & 18 & 0.830 \\
\hline
\end{tabular}

\section{Demographic traits}

We applied a multistate CMR analysis in 2 steps. The first step was to estimate age-specific survival (age-dependent model) and the second step was to assess the probability of skipping a breeding event, and to evaluate the potential effects of time and environmental covariates on these variables (Lebreton et al. 2009, Frederiksen et al. 2014). For a given sampling occasion, a storm petrel could be in one of 4 states: a pre-breeder (PB), breeder (B), skipper (S) or dead (D). The following observations could be made on a bird in the field: the individual was detected as chick and coded ' 1 ', the individual was detected as breeding adult and coded ' 2 ' or it went undetected and was coded ' 0 '. For the first step we used data of birds banded as chicks (3342 individuals) in the $23 \mathrm{yr}$ of study. We considered the 4 states, and 2 age classes: young (first year of age) and adult (older than 1 yr) (for more details see Soldatini et al. 2014). We tested for heterogeneity in survival (Pledger et al. 2003) by running the model with and without heterogeneity. We first ran the model with heterogeneity (Pradel et al. 2010), using mixture models with 2 classes of heterogeneity (Péron et al. 2010). Secondly, we ran the age-dependent model without heterogeneity (only 1 survival class). Afterwards, in both cases, we modelled age as a factor to ensure maximum flexibility in the modelling of the survival-age relationship (hence a nonparametric relationship). We used the Akaike information criterion (AIC) to select among models (Akaike 1973, Burnham \& Anderson 2002). The results of the goodness of fit (GOF) tests for the multistate model show the presence of transience and no trap-dependence (Table 1). The transience effect was probably due to an age effect on survival, which was accounted for by incorporating age as a qualitative covariate (Pradel et al. 1997). The CMR models were fitted using the program E-SURGE (Choquet et al. 2009b), while GOF tests (Pradel et al. 2005) were performed using the program U-CARE (Choquet et al. 2009a).

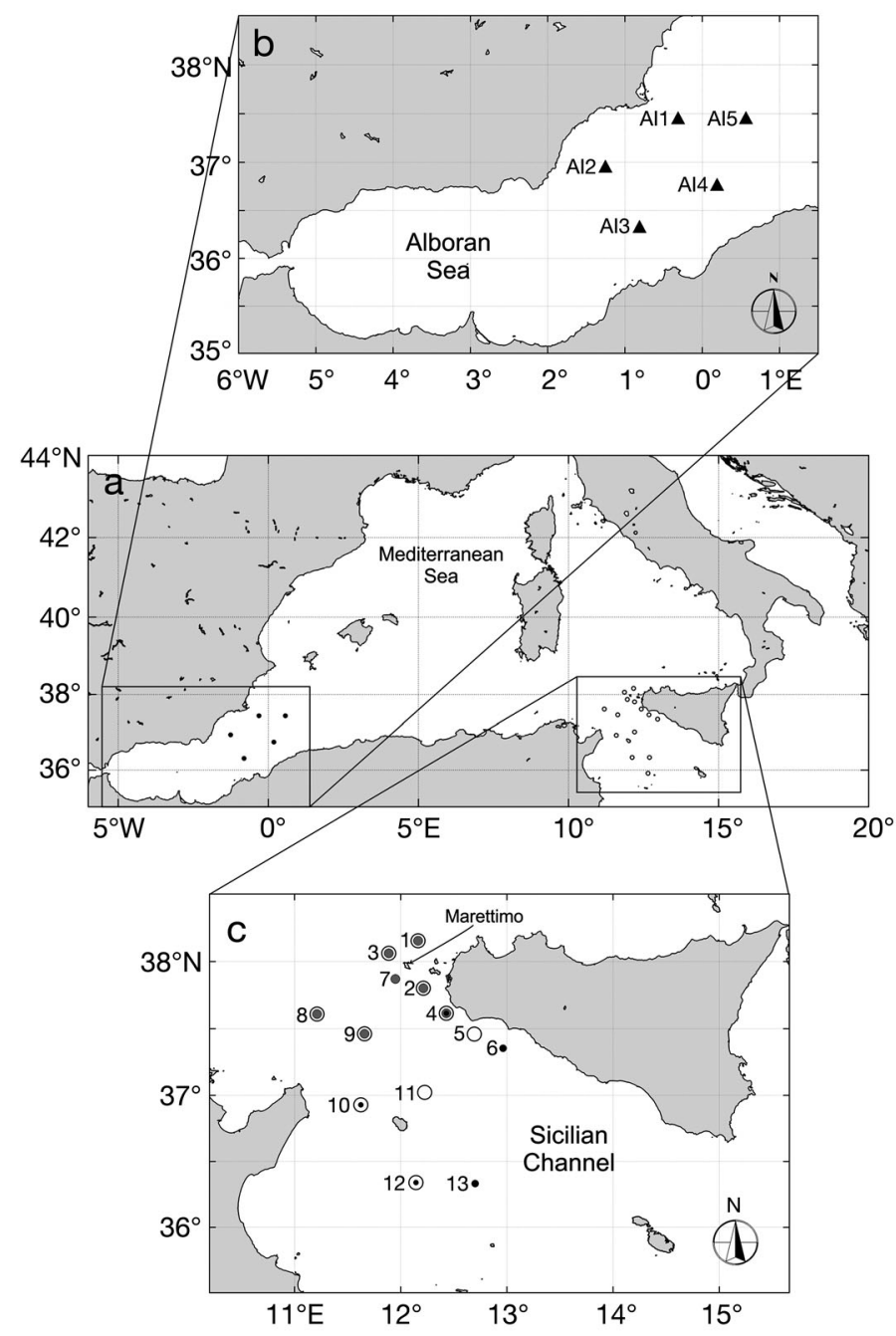

Fig. 1. (a) At-sea sampling points (open and filled circles in boxes) in the Mediterranean Sea from which time series of sea surface temperature (SST) were obtained to study the impact of SST on the demographics of Mediterranean storm petrels; (b) the 5 sampling points in the Alboran Sea (triangles); (c) the 13 random at-sea sampling points in the Sicilian Channel subdivided into 3 sub-sets: 5 points from the southern part of the channel (PB5SST; black dots), 7 points from the northern part (PB7SST; medium grey circles) and 10 points taken from the total area considered (PB10SST; white circles); note that sites can belong to multiple groups

\section{Skipping probability and climatic conditions}

We then ran the CMR model again, as a second step, and considered time-series data of SST in the Sicilian Channel (Fig. 1) - an area with upwelling conditions (Massetti 2004) — from 1991 to 2013 as a proxy for environmental conditions and food availability (Rayner et al. 2006, Gremillet et al. 2008). We decided to use March-April SST in the Sicilian Channel as it is the period when storm petrels are 
prospecting the colony, and therefore living in the area and using local resources. Storm petrels feed on Mysidacea and larval stages of fishes (AlboresBarajas et al. 2011), which are directly affected by SST. Hence, sea conditions of March-April will indirectly affect the body condition of storm petrels in late May, when they usually start breeding. We did not consider SST in winter in the Sicilian Channel as in previous analyses it was not correlated to breeding and survival (Soldatini et al. 2014).

In order to test for carry-over effects from wintering to breeding periods we considered the winter North Atlantic Oscillation (Climate Prediction Center 2008b), due to its broad geographic coverage, and winter range SST from the Alboran Sea (Soldatini et al. 2014). In this second step analysis, we used the complete CMR dataset of birds ringed as chicks and adults (5168 individuals).

We defined 3 environmental covariates to examine the direct effects of sea conditions during pre-breeding and winter periods on the propensity of skipping a breeding event: pre-breeding period SST (PBSST), the winter North Atlantic Oscillation (WNAO), and SST at wintering locations in the Alboran Sea (wAl). We selected PBSST data from 3 sets of samples taken at random at-sea sampling points during the prebreeding period (from March to April) from 1991 to 2013. As a proxy of winter conditions, we analysed North Atlantic Oscillation index data from December to February and used the average value of the selected period to represent WNAO (Climate Prediction Center 2008b). The covariate wAl is the principal component 1 (PC1) factor (82\% of explained variance) of a principal component analysis (PCA) of SST based on 5 sampling points in the Alboran Sea (Soldatini et al. 2014). We also used the El Niño Southern Oscillation index (ENSO) for January to March (Climate Prediction Center 2008a).

Data were from NASA Earth Observations products: SST data from the NOAA/NASA Advanced Very High Resolution Radiometer (AVHRR) Pathfinder Project and imagery processed by NASA Ocean Color Group from Moderate Resolution Imaging Spectroradiometer (MODIS) on NASA's Aqua satellite; all freely available at http://neo.sci.gsfc.nasa.gov/view.php? datasetId=MYD28M.

In order to identify the area where oceanic conditions during the pre-breeding period may directly affect storm petrel reproductive behaviour, we selected 13 random at-sea sampling points in the Sicilian Channel and then subdivided the area into 3 subsets: 5 sampling points from the southern half of the Sicilian Channel (PB5SST), 7 sampling points from the northern half (PB7SST) and 10 sampling points taken from the total area considered in the study (PB10SST; Fig. 1). We expressed oceanographic covariates (SST of the 3 sets of at-sea sampling points) as anomalies relative to the mean [anomaly $=$ (value - mean) $/$ mean] (Jenouvrier 2013). We performed 3 PCAs, one for each set of sampling points, in order to define variables to be used in the model (Grosbois et al. 2008) (see Supplement 1 at www.int-res.com/articles/ suppl/m552p255_supp.pdf). The pre-breeding period SST was summarized through PCAs as 3 external covariates: PC1 of the PB10SST $(94.7 \%$ of explained variance), PC1 of PB7SST: (95.4\% of explained variance) and PC1 of PB5SST (93.8\% of explained variance). We then used the PC1 factors, representatives of SST variation in the areas considered, as explanatory environmental covariates in the CMR models. PC factors embody cumulative direction of variation of the variables considered; in this study, negative PC1 values correspond to higher SST and positive values to lower SST (see Supplement 1).

In order to choose the best result from multiple significance tests of the 3 different covariates representing SST recorded in the 3 at-sea sampling-point sets, we applied the false discovery rate (FDR) for multiple testing following the method of Benjamini \& Hochberg (1995). We then applied the analysis of deviance (ANODEV) to assess significance of each covariate and calculated the proportion of deviance explained by these covariates using the $\mathrm{R}^{2}$ statistic (Grosbois et al. 2008).

We estimated the probability of breeders entering the skipping state (transition from state B to state S). We tested the effects of the environmental covariates both on survival and on the probability of skipping; together with linear effects, we tested quadratic effects of covariates. We also tested for correlation between pre-breeding external covariates and number of researchers' visits to the colony in order to exclude the possibility that the number of visits to the colony may have independently influenced the results.

PCAs, correlation, FDR, ANODEV and $\mathrm{R}^{2}$ statistics were computed using R v. 2.15.1 (R Development Core Team 2014) with significance defined as $\mathrm{p}<$ 0.05 for all analyses.

\section{Population growth rates and extinction probabilities}

Using survival and reproduction probabilities estimated in this and a previous study (Soldatini et al. 2014) we built Leslie matrices (Tuljapurkar 1993, 
Caswell 2001, Tuljapurkar et al. 2003) for 11 scenarios and calculated population growth rate $(\lambda)$ to investigate the effect of age and climate variability. We constructed and analysed age-structured matrix population models (see Supplement 2 at www.intres.com/articles/suppl/m552p255_supp.pdf). Survival rates in the first year and subsequent years were set according to CMR model results and age of first reproduction was set at Year 2 (Soldatini et al. 2014). We did not set an age of last reproduction as we found 23 year old breeders; thus the possible breeding period goes beyond the limits of our dataset.

We modelled different scenarios embodying our predictions under future climate conditions. In Scenario A, we accounted for higher mortality at Years 6 to 8 and possible senescence after Year 16 (using demographic parameters from this study, see Fig. 2), while in Scenario B we ignored the age effect and only considered average survival of juveniles and adults (demographic parameters from Soldatini et al. 2014). The subsequent 9 scenarios accounted for senescence (Scenario A) and considered environmental variability. In other words, we modified Scenario A by manipulating the proportion of breeding individuals according to the skipping model results (the 9 scenarios and their characteristics are summarized in Table 2).

As a result of the first part of our analysis, we obtained, in some years $(1997,1998,2003,2011$ and 2012), a strong effect between cold SST anomaly events (average anomaly $-0.37^{\circ} \mathrm{C}$ ) and increased probability of skipping. We recorded 3 such events during the study period, approximately once every $5 \mathrm{yr}$. We extrapolated the SST anomaly threshold of $-0.37^{\circ} \mathrm{C}$ as representative of extreme conditions calculated as the mean of SST anomalies in the 3 years with higher skipping probability. We then used a Bernoulli distribution in order to implement the frequency of SST anomaly events and skipping probability variation. For each scenario we built a stochastic matrix model and calculated the stochastic population growth rate and extinction probability (through simulations) using a pseudo extinction threshold of 100 individuals and time spans of 100 and 200 yr. Scenarios included real and simulated skipping probabilities as an effect of the strength and frequency of SST anomalies. We simulated a situation with no SST anomaly events and a $15 \%$ skipping probability and then with the actual frequency and strength of SST anomaly events with $45 \%$ skipping probability, and finally with colder SST anomaly events and $65 \%$ skipping probability. We modified the percentage of breeding females in the Leslie matrix using previous values with different frequencies simulating actual conditions (every $5 \mathrm{yr}$ ) and more and less frequent SST anomaly events (i.e. every 3 and $10 \mathrm{yr}_{\text {; }}$ see Table 2).

Data were analysed using the 'popbio' (Stubben et al. 2012) and 'popdemo' (Stott et al. 2011, 2012) packages available for R v. 2.15.0 (R Development Core Team 2014). We also wrote our own $R$ (partly reported in Supplement 2) code to run stochastic demographic models.

\section{RESULTS}

\section{Age-dependent survival}

We found no heterogeneity in our study population $(\triangle \mathrm{AIC}=6.000$, Models 5 and 6 in Table 3$)$. We observed a time effect on survival. Senescence started after Year 16 (Fig. 2) in an age-dependent model run without heterogeneity on $23 \mathrm{yr}$ of CMR data. Before Year 16, average survival in adults was 0.95, while from Years 17 to 21 average survival was 0.36 , suggesting senescence in the population. We also observed lower survival probability in Years 6 to 8 (average 0.78 ) compared to subsequent ages (Fig. 2).

Table 2. Description of 9 scenarios where the percentage of Mediterranean storm petrels skipping reproduction and the frequency of SST anomaly events in the Sicilian Channel were manipulated. The frequency of events is shown as the average return period, e.g. ' 3 ' indicates that an event occurs once every $3 \mathrm{yr}$. The column headed 'R/M' indicates whether conditions are real or manipulated, the first letter referring to percentage of skippers and the second to frequency of events. Stochastic population growth rates $\left(\lambda_{\mathrm{s}}\right)$ and extinction probability were calculated for each scenario after 100 and $200 \mathrm{yr}$

\begin{tabular}{|lccccc|}
\hline $\begin{array}{l}\text { Sce- } \\
\text { nario }\end{array}$ & $\begin{array}{c}\text { Skipping } \\
\text { per- } \\
\text { centage }\end{array}$ & $\begin{array}{c}\text { Fre- } \\
\text { quency } \\
\text { of events } \\
\text { (yr) }\end{array}$ & R/M & $\begin{array}{c}\lambda_{\mathrm{s}} \text { after } \\
100 / 200 \mathrm{yr}\end{array}$ & $\begin{array}{c}\text { Extinction } \\
\text { probability } \\
\text { after } \\
100 / 200 \mathrm{yr}\end{array}$ \\
\hline 1 & 65 & 5 & $\mathrm{R}-\mathrm{R}$ & $0.984 / 0.985$ & $0 / 0.304$ \\
2 & 65 & 3 & $\mathrm{R}-\mathrm{M}$ & $0.974 / 0.975$ & $0.126 / 1$ \\
3 & 65 & 10 & $\mathrm{R}-\mathrm{M}$ & $0.991 / 0.993$ & $0 / 0$ \\
4 & 15 & 5 & $\mathrm{M}-\mathrm{R}$ & $0.995 / 0.997$ & $0 / 0$ \\
5 & 15 & 3 & $\mathrm{M}-\mathrm{M}$ & $0.993 / 0.995$ & $0 / 0$ \\
6 & 15 & 10 & M-M & $0.997 / 1$ & $0 / 0$ \\
7 & 45 & 5 & M-R & $0.989 / 0.990$ & $0 / 0$ \\
8 & 45 & 3 & M-M & $0.982 / 0.983$ & $0 / 0$ \\
9 & 45 & 10 & M-M & $0.993 / 0.995$ & $0 / 0$ \\
\hline
\end{tabular}


Fig. 2. Estimated survival probability for Mediterranean storm petrels as a function of age (yr). Grey dotted lines show 95\% confidence intervals. The estimates are from the best model, $\Phi$ t Pt (no het) (Model 1 in Table 3)

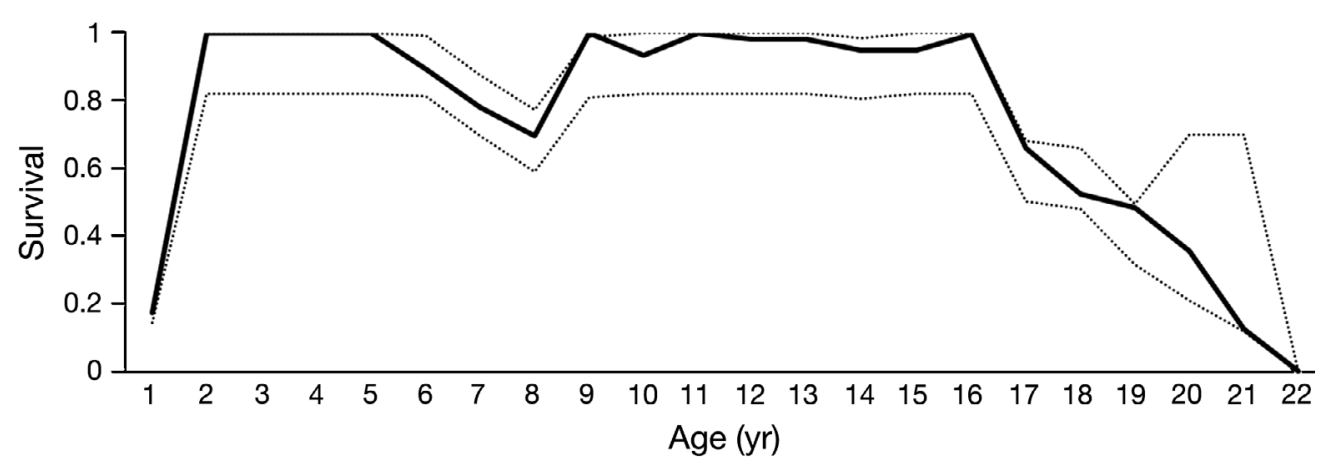

\section{Skipping probability and oceanographic conditions}

We used PB10SST, PB7SST and PB5SST as covariates in the model testing the influence of oceanographic conditions on skipping probability. The FDR test showed that all 3 covariates had a significant effect (Table 4). We thus selected the PB7SST data based on results of the ANODEV $\left(F_{1,28}=4.364, \mathrm{p}=\right.$ 0.049 , see Table 4 for more details) as the pre-breeding period external covariate for subsequent analysis. Winter conditions were represented by wAl and WNAO. External covariates were not correlated (PB7SST vs. wAl: $\mathrm{r}=0.419, \mathrm{p}=0.176$; PB7SSt vs. WNAO: $r=-0.133, p=0.683$; wAl vs. WNAO: $r=0$, $\mathrm{p}=1$ ).

The highest-ranked model is the one that included oceanographic forcing. In fact, the best model indicated a PBSST condition-dependent probability of entering the skipping state for breeders. Age of individuals and winter condition in the Alboran Sea influenced survival while local SST in March-April influenced the probability of breeding both in the case of recruiting individuals and adult breeders. Both covariates were demonstrated to have a quadratic effect respectively on survival and skipping propensity. Local SST anomaly measured at 7 sampling points (PB7SST) had an inversely proportional effect on recruitment age and on the probability of entering the skipping state for breeders. SST variation in the northern part of the Sicilian Channel explained $18 \%$ of the temporal variation in skipping probabilities (Table 4); this suggests that SST influences breeding decisions in Marettimo colonies. High skipping probabilities were synchronized with years corresponding to peaks in the SST PC1 values (Fig. 3). We observed lower skipping probabilities (on average $0.11 \%$ ) in years with warmer SST in the northern Sicilian Channel (corresponding to an average anomaly of $+0.37^{\circ} \mathrm{C}$ ). On the other hand, higher skipping probabilities (on average $0.65 \%$ ) were related to colder March-April SST (corresponding to an average anomaly of $-0.37^{\circ} \mathrm{C}$ ) (Fig. 3). However, in years 1997 and 1998 there were high percentages of skipping individuals not properly predicted by SST (Fig. 3).

Table 3. Age-dependent model selection, focusing on survival and encounter probabilities for Mediterranean storm petrels. Only the best models are presented. The effects of survival $(\Phi)$, time $(\mathrm{t})$, and age (a) were considered on encounter probability $(\mathrm{P})$. het = heterogeneity. Deviance, the number of parameters (NP) and Aikake information criteria (AIC) values (Burnham \& Anderson 2002) are reported. The preferred model is in bold

\begin{tabular}{|c|c|c|c|c|}
\hline No. & Model & Deviance & NP & AIC \\
\hline 1 & Фt Pt (no het) & 3174.3 & 45 & 3264.3 \\
\hline 2 & Фа Pt (no het) & 3203.7 & 45 & 3293.7 \\
\hline 3 & Фt P (no het) & 3278.8 & 24 & 3326.8 \\
\hline 4 & Фа P (no het) & 3349.2 & 24 & 3397.2 \\
\hline 5 & Ф P (no het) & 3414.6 & 4 & 3422.6 \\
\hline 6 & Ф P (het) & 3414.6 & 7 & 3428.6 \\
\hline
\end{tabular}

Table 4. Model selection, focusing on transition probabilities (from 'breeder' to 'skipper') for Mediterranean storm petrels. Sea surface temperature recorded at 5 (PB5SST), 7 (PB7SST) and 10 (PB10SST) points in the Sicilian Channel. Time (t), and constant effects (i) were considered on the probability of transition from 'breeder' to 'skipper' ( $\Psi)$. AIC values, deviance, the number of parameters (NP), results of analysis of deviance (ANODEV), $\mathrm{R}^{2}$ tests, and $\mathrm{p}$-values based on the $F$-distribution and the false discovery rate (FDR) are reported. The preferred model is in bold

\begin{tabular}{|lccccccc|}
\hline Model & AIC & $\begin{array}{c}\text { De- } \\
\text { viance }\end{array}$ & NP & $\begin{array}{c}\text { ANODEV } \\
\text { test }\end{array}$ & $\begin{array}{c}\mathrm{R}^{2} \\
(\%)\end{array}$ & $\mathrm{p}$ & $\begin{array}{c}\text { FDR } \\
\mathrm{p}\end{array}$ \\
\hline$\Phi_{\mathrm{t}} \Psi_{\mathrm{t}}$ & 10988.4 & 10932.4 & 28 & & & & \\
$\Phi_{\mathrm{t}} \Psi_{\text {PB10SST }}$ & 11241.1 & 11225.1 & 8 & 0.006 & 0 & 0.937 & 0.010 \\
$\Phi_{\mathrm{t}} \Psi_{\text {PB5SST }}$ & 11196.6 & 11180.6 & 8 & 3.590 & 15 & 0.072 & 0.006 \\
$\boldsymbol{\Phi}_{\mathrm{t}} \Psi_{\text {PB7SST }}$ & $\mathbf{1 1 1 8 8 . 7}$ & $\mathbf{1 1 1 7 2 . 7}$ & $\mathbf{8}$ & $\mathbf{4 . 3 6 4}$ & $\mathbf{1 8}$ & $\mathbf{0 . 0 4 9}$ & $\mathbf{0 . 0 0 3}$ \\
$\Phi_{\mathrm{i}} \Psi_{\mathrm{i}}$ & 11239.2 & 11225.2 & 7 & & & & \\
\hline
\end{tabular}




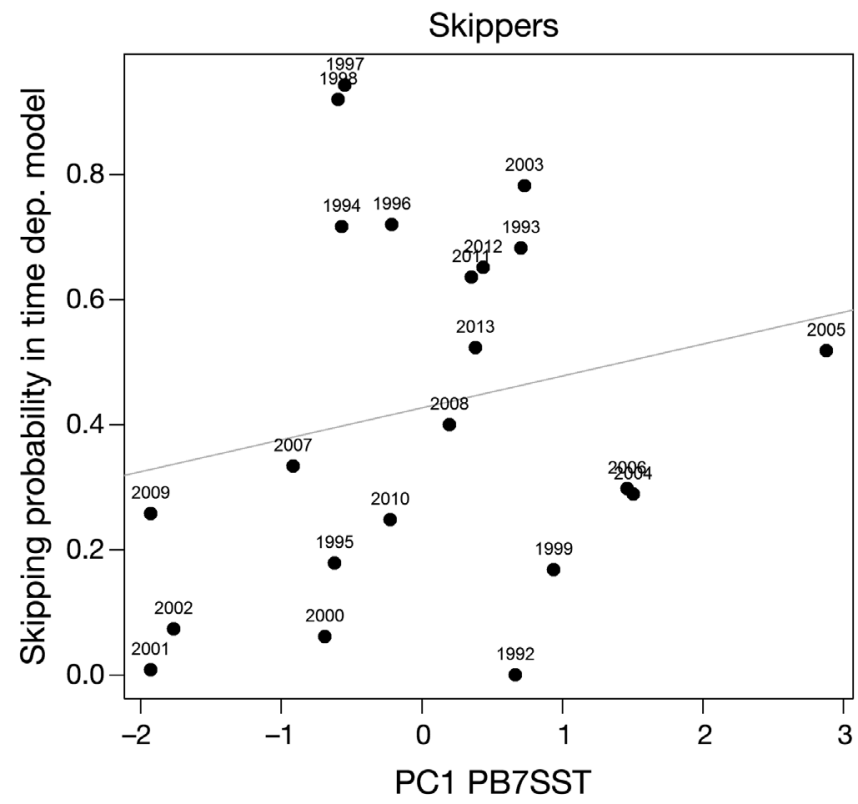

Fig. 3. Linear regression of the skipping probability for Mediterranean storm petrels estimated by the timedependent (dep.) model ( $\Phi \mathrm{t} \Psi \mathrm{t}$, see Table 5 for details) as a function of values of the first principal component factor (PC1) of a principal component analysis (PCA), based on SST of 7 at-sea sampling points during the pre-breeding period (PB7SST). The regression line is shown in gray, points represent single year values

When considering wintering conditions effects at the probable wintering range or on a wider basis, we detected an additive effect of age and wintering range conditions (i.e. wAl) on survival, while prebreeding period SST (i.e. PB7SST) influenced skipping probability (Table 5, Fig. 4). WNAO and ENSO had a negligible influence on skipping probability.

Our results were robust in capturing effort variability in the study period, as we found no correlation between PB7SST and catch effort $(r=0.121)$.
Table 5. Influence of environmental variables on Mediterranean storm petrel demographics: model selection results. The effects of sea surface temperature recorded at 7 sampling points in the Sicilian channel (PB7SST), winter NAO (WNAO) recorded in December through February, SST in the Alboran Sea, the potential wintering range recorded in December through February (wAl), El Niño Southern Oscillation index (ENSO), age (a), time (t), and constant effects (i) on survival $(\Phi)$, the transition probability from state 'breeder' to 'skip-

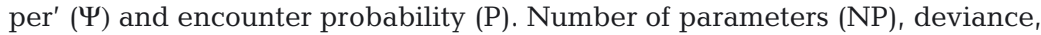
AIC and $\triangle \mathrm{AIC}$ values are reported. The preferred model is in bold

\begin{tabular}{|c|c|c|c|c|}
\hline MDL & NP & Deviance & AIC & $\Delta \mathrm{AIC}$ \\
\hline$\Phi a+w A l^{2} \Psi$ PB7SST $^{2}$ Pt & 53 & 9726.134 & 9832.134 & 75.507 \\
\hline Фа+wAl ЧPB7SST Pt & 53 & 9801.641 & 9907.641 & 489.578 \\
\hline Фа+wAl ЧРB7SST Pa & 53 & 10291.219 & 10397.219 & 41.791 \\
\hline Фа+wAl ЧPB7SST & 46 & 10347.010 & 10439.010 & 2.602 \\
\hline Фа+PB7sst $\Psi$ wAl & 46 & 10349.613 & 10441.613 & 6.324 \\
\hline$\Phi \mathrm{a}+\mathrm{PB}_{\mathrm{sst}}{ }^{2} \Psi \mathrm{wAl}{ }^{2}$ & 46 & 10355.938 & 10447.938 & 170.252 \\
\hline Фa+wAl ЧPB7SST+ENSO Pt & 56 & 10510.11 & 10618.19 .13 & 3.94 \\
\hline$\Phi \mathrm{a}+\mathrm{WAl}^{2} \Psi \mathrm{PB}^{2} \mathrm{SST}^{2}+\mathrm{ENSO}^{2} \mathrm{Pt}$ & t 56 & 10510.11 & 10622.13 & 13.436 \\
\hline$\Phi \mathrm{t} \Psi \mathrm{t}$ & 85 & 10465.566 & 10635.566 & 111.989 \\
\hline Фа $\Psi а$ & 64 & 10619.555 & 10747.555 & 1.536 \\
\hline ФWAl ЧPB7SST Pt & 31 & 10687.091 & 10749.091 & 234.602 \\
\hline ФРВ7SST Ча & 44 & 10895.693 & 10983.693 & 4.709 \\
\hline$\Phi \Psi \mathrm{t}$ & 28 & 10932.402 & 10988.402 & 41.344 \\
\hline Фа $\Psi 1 \mathrm{a} \Psi^{2} \mathrm{t}$ & 64 & 10901.746 & 11029.746 & 158.986 \\
\hline$\Phi \Psi P B 7 S S T$ & 8 & 11172.732 & 11188.732 & 34.575 \\
\hline$\Phi \Psi W N A O$ & 8 & 11207.307 & 11223.307 & 15.866 \\
\hline$\Phi \mathrm{i} \Psi \mathrm{i}$ & 7 & 11225.173 & 11239.173 & 2 \\
\hline$\Phi \Psi \mathrm{wAl}$ & 8 & 11225.173 & 11241.173 & 28.318 \\
\hline Фа $\Psi W N A O$ & 44 & 11181.491 & 11269.491 & 1.682 \\
\hline$\Phi \Psi 1 \mathrm{a} \Psi^{2} \mathrm{wAl}$ & 23 & 11225.173 & 11271.173 & 0 \\
\hline Фа ЧРВ7SST & 23 & 11225.173 & 11271.173 & 1.879 \\
\hline$\Phi w A l ~ \Psi w A l$ & 24 & 11225.052 & 11273.052 & 0 \\
\hline$\Phi \mathrm{wAl} \Psi 1 \mathrm{a} \Psi^{2} \mathrm{~PB} 7 \mathrm{SST}$ & 24 & 11225.052 & 11273.052 & 8.933 \\
\hline Фа ЧPB7SST & 45 & 11191.985 & 11281.985 & 0.382 \\
\hline Фа $\Psi 1 \mathrm{~PB} 7 \mathrm{SST} \Psi^{2} \mathrm{WAl}$ & 44 & 11194.367 & 11282.367 & 0 \\
\hline Фа $\Psi_{\mathrm{wAl}}$ & 44 & 11194.367 & 11282.367 & \\
\hline
\end{tabular}

\section{Population growth rate}

We found a difference in long term population growth rate between Scenarios $\mathrm{A}$ and $\mathrm{B}\left(\lambda_{\mathrm{A}}=1.005\right.$ and $\lambda_{\mathrm{B}}=$ 1.032) indicating that the population is viable in a deterministic environment according to the minimum viable population definition, i.e. when the smallest population has at least a $95 \%$ chance of persistence in $200 \mathrm{yr}$ (Newton 1998).

In the 9 scenarios analyzed, as a modification of Scenario A obtained by accounting for real and potential environmental variability constraints, we estimated stochastic population growth rates from 0.974 to 0.997 (Table 2) in the next $100 \mathrm{yr}$ with generally no pseudo-extinction probability, with the exceptions of Scenario 1 considering the next $100 \mathrm{yr}$ and Scenarios 1 and 2 considering the next $200 \mathrm{yr}$.

In fact, Scenarios 1 and 2 were the exception, where the continuation of the current situation (Scenario 1) or an increase in frequency of SST anomaly events would lead the colony to extinction. The analysis of these scenarios suggested that this population may decline in the future. 

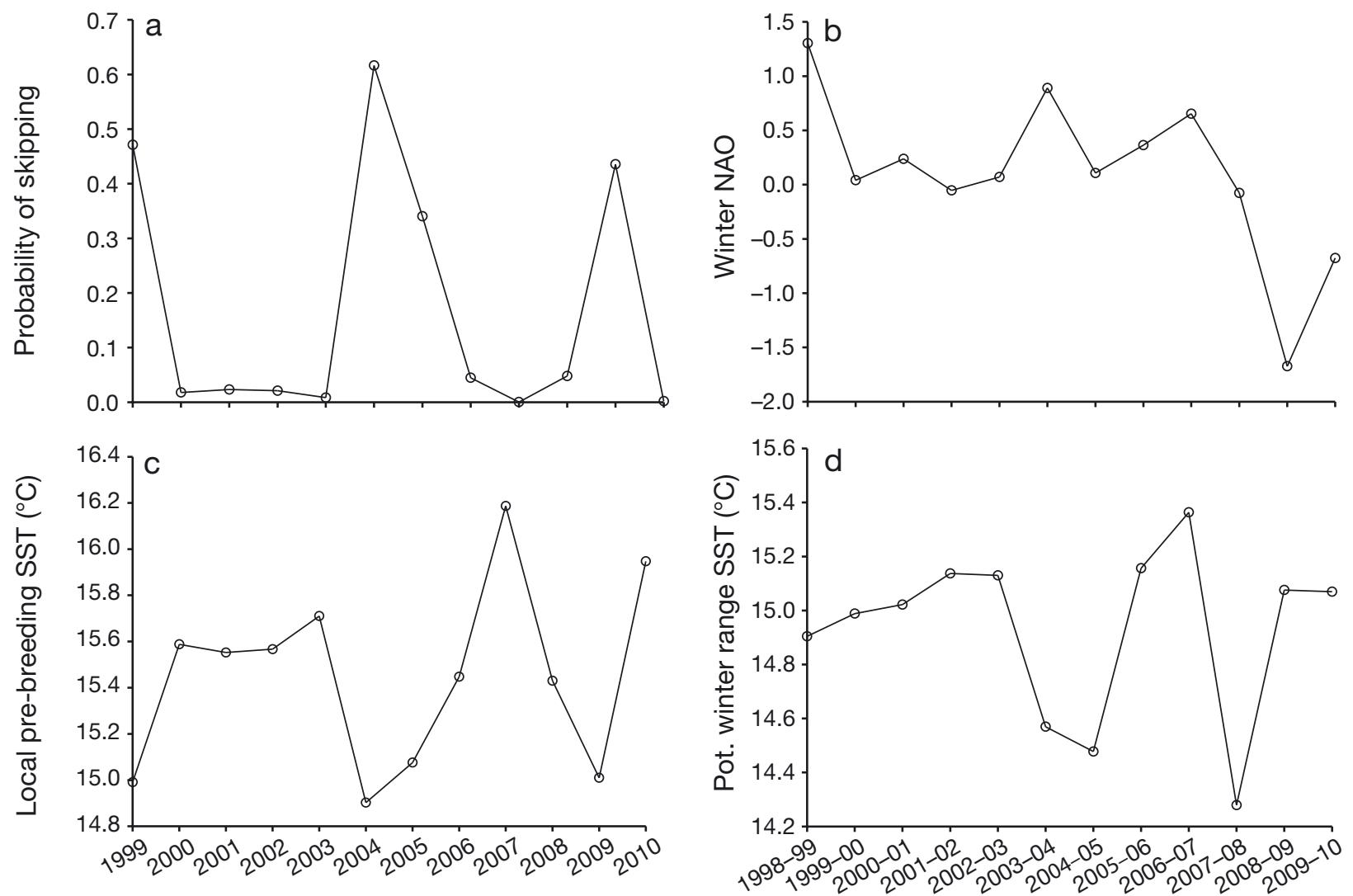

Fig. 4. Temporal trends in skipping probability for Mediterranean storm petrels and environmental conditions: (a) skipping probability estimated from the model $\Phi$ a+wAl $\Psi$ PB7SST Pt (see Table 5 for details) that accounts for the effect of age on survival and wintering site plus the effect of pre-breeding local site SST on skipping probability; (b) winter NAO; (c) local prebreeding period SST and (d) SST in the potential winter range, in the Alboran Sea. Panels (b) and (d) represent winter period datasets (December to February), so each label along the $x$-axis indicates $2 \mathrm{yr}$

Present conditions, with SST anomalies recorded once every $5 \mathrm{yr}$ period, will lead to a population reduction during the following decade (Scenario 1) and to probable extinction in the next 200 yr. More frequent (every 3 yr) SST anomalies would reduce population growth rate and probably lead to a high risk of extinction (probability of extinction $12.6 \%$ in $100 \mathrm{yr}$ and $100 \%$ in $200 \mathrm{yr}$; see Scenario 2 in Table 2). Scenario 3, with SST anomalies simulated to occur every $10 \mathrm{yr}$, resulted in the highest population growth rate out of the first 3 scenarios, although the value is lower than that estimated for constant environmental conditions (Scenario A). Simulating an improvement in sea condition (i.e. reduction in frequency of SST anomalies) with reference to this warm-condition selected species, we obtained a smaller proportion of skippers (15 or $45 \%$ of breeders) and population growth rates lower than those in a constant environment (i.e. no increase or decrease in SST anomalies), but in no case leading to pseudoextinction in the next 100 or $200 \mathrm{yr}$. An SST anomaly event every 10 yr would probably reduce the popula- tion growth rate without leading it to extinction (Scenarios 3, 6 and 9). Scenarios 4, 5 and 6 simulated lower skipping probabilities, which could occur as a result of the adaptation of the species to SST anomalies or a reduction of SST cold anomalies. This would result in an improvement of population growth rates and a zero probability of extinction. On the other hand, a reduction in the proportion of skippers, in the case of favorable change of oceanographic conditions or as a consequence of a new adaptive strategy of the population to unfavourable conditions (e.g. shifting wintering range or diet), would result in an increase in population growth rates (Scenarios 5, 6 and 9).

\section{DISCUSSION}

\section{Storm petrel mortality and senescence}

Demographic and ecological traits of Mediterranean storm petrels have recently been studied 
thanks to the availability of long time series of CMR data (Sanz-Aguilar et al. 2008, 2009, 2010, Soldatini et al. 2014). This has provided information on differential age class survival and recruitment of the species (Sanz-Aguilar et al. 2009, Soldatini et al. 2014), as the basis for further demographic analysis. In our study, we observed a reduction in survival probability after Year 16. This suggests that senescence starts at this age and thus that the population can be divided into 3 age classes: juveniles, adults and senescing individuals, as in other long-lived seabird species (Pardo et al. 2013). Senescing individuals have higher mortality compared to younger adults and could also be influenced by reproductive senescence as a consequence of altered foraging capacities of older individuals, in accordance with similar findings for black-browed albatross (Pardo et al. 2013). We found similar $\lambda$ in Scenarios A and B (respectively accounting or not for senescence); this may be explained by the fact that there were very few females alive after Year 16. Moreover, these females had a low reproductive value, therefore contributed little to the population growth rate and in turn had a small sensitivity. The estimates of the effect of senescence on population growth rate should be considered with caution and a more detailed description of the effect of senescence on population dynamics including reproductive senescence and its covariation with actuarial senescence would help in completing the picture (Robert et al. 2015).

\section{Pre-breeding period environmental conditions influence skipping propensity}

In addition to the mortality factor, population growth rate is obviously constrained by factors affecting reproductive behaviour, which thus helps shape storm petrel population dynamics. Of particular relevance to reproductive output is the prebreeding period, when individuals accumulate the resources required to afford breeding. Our results suggest that temperature is a good indicator of ecosystem state for these birds as they are sensitive to average anomalies of less than $1^{\circ} \mathrm{C}$. In particular, SST in the northern Sicilian Channel in March-April is important for the species, producing conditions that are suitable or not for breeding: high SST (average anomaly of $+0.37^{\circ} \mathrm{C}$ ) coincides with high breeding probability, while low SST (average anomaly of $-0.37^{\circ} \mathrm{C}$ ) will induce breeders to skip reproduction.
This latter situation probably coincides with unfavourable conditions in terms of prey availability in the Sicilian Channel. Although primary productivity at lower trophic levels may be increased by deep/ cool water upwelling enhancing the circulation of nutrients, negative SST anomalies may have a negative physiological influence, delaying fish development (Lafuente et al. 2002). Studies on fish population in this area have shown that sardine and anchovy biomass are negatively correlated with the mean SST in periods corresponding to larval and juvenile growth, resulting in a reduction in recruitment success and thereby also population size (e.g. Lafuente et al. 2002). In particular, Marettimo storm petrel colonies are located at the western inlet of the Sicilian Channel, where the 2 large Mediterranean sub-basins meet, resulting in the bifurcations of the surface and intermediate-depth water transports (Pierini \& Rubino 2001). The area is characterized by seasonal wind-induced water movements, particularly in the spring period when winds from the north over the western basin and winds from the south-east over the the eastern basin meet, generating Ekman transport (Bakun \& Agostini 2001). Geostrophic fronts in the area facilitate the pumping of nutrients from deep layers, and warm SSTs speed up the development of eggs and larvae (Lafuente et al. 2002). When waters are colder, this process may be altered, affecting storm petrels whose diet depends on larval and juvenile stages of fishes (Albores-Barajas et al. 2011). Further investigation on the sensitivity of the marine food web and possible mismatches caused by variable oceanographic conditions (Ramírez et al. 2016) would clarify this point.

\section{Only strong climatic oscillations influence skipping propensity}

An interesting point is that in years 1997 and 1998 we observed a high percentage of skipping not correlated to SST. We did not observe a significant effect of ENSO on our study population but we hypothesize that petrels do detect an ENSO signal but only during exceptionally strong events, given that strong ENSO years correspond to higher skipping probability. This observation may support the results of climatological studies showing that exceptionally strong El Niño events have an influence on North Atlantic and Mediterranean rainfall regimes and SST (Pozo-Vázquez et al. 2001, Mariotti et al. 2002, Shaman \& Tziperman 2011). 


\section{Carryover effect of winter conditions}

We found that winter environmental conditions affected survival, in addition to constraints posed by pre-breeding SST on skipping. A possible explanation is that survivors are likely recovering from a bad winter, of which low SST in the Sicilian Channel is probably a consequence. Thus, birds are more likely to skip breeding after cold winters and in cold prebreeding periods. Our findings that the western Mediterranean basin conditions during winter and spring affect the probability of breeding in the Mediterranean storm petrel is in agreement with studies on other species (Reed et al. 2015).

\section{Forecasting the impacts of ocean warming}

In the case of SST rise as a consequence of climate change (Kovats et al. 2014), changes in fluid circulation may have a strong effect on storm petrel demography. The fact that $>60 \%$ of the potential breeders skip reproduction in response to a negative SST anomaly of $-0.37^{\circ} \mathrm{C}$ is alarming. The high degree of philopatry suggests that changes negatively affecting reproduction in the Marettimo population, the largest known colony of these storm petrels (Mante \& Debize 2012), may have catastrophic consequences for the subspecies. Seabirds that have adapted to periodic oscillations of the marine environment may not move from their breeding areas even if these have become sub-optimal. Instead, they may opt to skip reproduction (Cubaynes et al. 2011). Our findings are in accordance with the prudent parent hypothesis (Drent \& Daan 1980, Le Bohec et al. 2007) as birds are synchronous in skipping reproduction in years with unfavourable conditions. This strategy may enhance adaptation to a changing environment, as a form of bet-hedging (Crean \& Marshall 2009, Ripa et al. 2010). Alternatively it may have a link to breeder intrinsic quality as in other Mediterranean seabird species (Sanz-Aguilar et al. 2011).

By considering SST anomalies as the cause of reduction in fecundity, we found that the increase in skipping frequency directly and negatively affected the population growth rate. Given that Scenario 1 closely reflects current conditions, we may expect the Marettimo population to decrease and face risk of extinction, i.e. falling below the minimum viable population threshold (Newton 1998), in the next $200 \mathrm{yr}$. The decreasing trend projected for this population (around $22 \%$ in $100 \mathrm{yr}$ ) is in accordance with general seabird population trends, which have recorded a decrease of $69.7 \%$ in the last $60 \mathrm{yr}$ (Paleczny et al. 2015). In addition to environmental stochasticity, human activities such as commercial fisheries may have a direct or indirect effect on petrels by depleting the standing and spawning biomass of prey species. Taking into account this human impact on the trophic web, and its likely indirect effect on the skipping propensity of the storm petrel, would complete the picture, probably revealing that the situation is worse than previously thought.

Changes in the eastern Mediterranean SST show a $\sim 5 \%$ annual increase over the period 1990 to 2014 (Van Houtan et al. 2015). In the case of an increase in frequency of cold winter conditions, the Marettimo population would manifest an increase in skipping years with an overall reduction in reproductive output, while the population may not be negatively affected by SST changes if the present trend is confirmed. In fact, a concrete improvement in the demographic trend would result from a decrease in the frequency of cold SST anomalies and a general increase in temperatures, as forecasted (Parry et al. 2007, Giorgi \& Lionello 2008, Kovats et al. 2014). Furthermore, in years with warmer conditions, lower chick mortality is also expected due to drier conditions in nesting caves (Soldatini et al. 2014). On the other hand, future climate projections are complex, and comprise changes other than warming, especially for upwelling systems. In fact, a cautious approach is needed, as high breeding success during present warm SST conditions in the Mediterranean does not mean that the trophic dynamics in the future will support a similar food web. Storm petrels, and seabirds in general, would be negatively affected by an upwelling displacement or shutdown due to a warmer climate (Karnauskas et al. 2015).

\section{Concluding remarks}

This study probably underestimates $\lambda$ values, as we only considered data from accessible nests $(10 \%)$ of a colony of about 2500 individuals (Albores-Barajas et al. 2012), and for this reason, our results may be biased toward a worst-case scenario. The high philopatry and resultant sensitivity to climatic niche variation of the species suggest that the population has a generally low level of robustness to climate change (Jenouvrier 2013). With particular reference to the forecasted conditions, the climatic issue may not negatively affect the species, although the effects of anthropogenic overexploitation of sea resources remain uncertain. 
Our particular goal was to unravel demographic traits (senescence and skipping behaviour) of a poorly known seabird species and link them to environmental variability using a forecasting approach. Our findings confirm that population demography in marine systems is sensitive to environmental variation through interactions between mortality and reproduction-dependent effects, in agreement with studies from other geographic areas (Barbraud \& Weimerskirch 2003). Our results provide strong evidence for the influence of oceanographic variables on seabird skipping propensity, while climatic indices are less significantly related. Other Mediterranean seabird species such as Scopoli's shearwater Calonectris diomedea and Yelkouan shearwater Puffinus yelkouan, are most probably facing similar reproductive constraints due to environmental variation (Hamer 2010, Sanz-Aguilar et al. 2011). Confinement to the Mediterranean basin may present a problem for these seabird species, as the Mediterranean allows only limited north-south shifts of habitat and in phenology, in contrast with other seas (Weimerskirch et al. 2003, Barbraud \& Weimerskirch 2006), thus requiring a high level of species resilience to environmental variation.

Acknowledgements. We are particularly grateful to David Koons for making available the codes for the analysis of environmental stochasticity, and for his comments that greatly improved the manuscript. We thank Kyle Van Houtan and 3 anonymous referees for their useful and encouraging revision of the manuscript. We are also grateful to Emanuela Canale, Fabio Lo Valvo, Paolo Lucido and Marcello Tagliavia for helping in the field. Our thanks go to Alejandro Ramos, Dimitri Giunchi and Carlo Catoni for their valuable help in spatial data processing and to Andrew O'Reilly-Nugent for language editing. This study was conducted using NASA Earth Observations products. Cecilia Soldatini was involved in the project CICESE 691111.

\section{LITERATURE CITED}

Agostini VN, Bakun A (2002) 'Ocean triads' in the Mediterranean Sea: physical mechanisms potentially structuring reproductive habitat suitability (with example application to European anchovy, Engraulis encrasicolus). Fish Oceanogr 11:129-142

Ainley D, Russell J, Jenouvrier S, Woehler E, Lyver POB, Fraser WR, Kooyman GL (2010) Antarctic penguin response to habitat change as Earth's troposphere reaches $2^{\circ} \mathrm{C}$ above preindustrial levels. Ecol Monogr 80:49-66

Akaike H (1973) Information theory and an extension of the maximum likelihood principle. In: Petrov BN, Csaki BF (eds) Proc 2nd Int Symp on Information Theory. Akademiai Kiado, Budapest, p 267-281

Albores-Barajas YV, Riccato F, Fiorin R, Massa B, Torricelli P, Soldatini C (2011) Diet and diving behaviour of the Mediterranean storm petrel (Hydrobates pelagicus melitensis). Bird Study 58:208-212
Albores-Barajas YV, Massa B, LoCascio P, Soldatini C (2012) Night surveys and smell, a mixed method to detect unknown colonies of storm petrel (Hydrobates pelagicus). Avocetta 36:95-96

- Bailey LD, van de Pol M (2016) Tackling extremes: challenges for ecological and evolutionary research on extreme climatic events. J Anim Ecol 85:85-96

Bakun A, Agostini VN (2001) Seasonal patterns of windinduced upwelling/downwelling in the Mediterranean Sea. Sci Mar 65:243-257

Barbraud C, Weimerskirch H (2003) Climate and density shape population dynamics of a marine top predator. Proc R Soc B 270:2111-2116

Barbraud C, Weimerskirch H (2005) Environmental conditions and breeding experience affect costs of reproduction in blue petrels. Ecology 86:682-692

- Barbraud C, Weimerskirch H (2006) Antarctic birds breed later in response to climate change. Proc Natl Acad Sci USA 103:6248-6251

Barbraud C, Rivalan P, Inchausti P, Nevoux M, Rolland V, Weimerskirch $H$ (2011) Contrasted demographic responses facing future climate change in Southern Ocean seabirds. J Anim Ecol 80:89-100

Baron JP, Le Galliard JF, Ferrière R, Tully T (2013) Intermittent breeding and the dynamics of resource allocation to reproduction, growth and survival. Funct Ecol 27: 173-183

Baum JK, Worm B (2009) Cascading top down effects of changing oceanic predator abundances. J Anim Ecol 78: 699-714

Benjamini Y, Hochberg Y (1995) Controlling the false discovery rate: a practical and powerful approach to multiple testing. J R Stat Soc B 57:289-300

Bladé I, Liebmann B, Fortuny D, van Oldenborgh GJ (2012) Observed and simulated impacts of the summer NAO in Europe: implications for projected drying in the Mediterranean region. Clim Dyn 39:709-727

Burnham KP, Anderson DR (2002) Model selection and multimodel inference: a practical information-theoretic approach. Springer, New York, NY

Calladine J, Harris M (1997) Intermittent breeding in the herring gull Larus argentatus and the lesser black backed gull Larus fuscus. Ibis 139:259-263

Cam E, Hines JE, Monnat JY, Nichols JD, Danchin E (1998) Are adult nonbreeders prudent parents? The kittiwake model. Ecology 79:2917-2930

Caswell H (2001) Matrix population models. Sinauer, Sunderland, MA

Chambers LE, Devney CA, Congdon BC, Dunlop N, Woehler EJ, Dann P (2011) Observed and predicted effects of climate on Australian seabirds. Emu 111:235-251

> Chambers LE, Patterson T, Hobday AJ, Arnould JP, Tuck GN, Wilcox C, Dann P (2015) Determining trends and environmental drivers from long-term marine mammal and seabird data: examples from Southern Australia. Reg Environ Change 15:197-209

> Choquet R, Lebreton JD, Gimenez O, Reboulet AM, Pradel R (2009a) U-CARE: utilities for performing goodness of fit tests and manipulating CApture-REcapture data. Ecography 32:1071-1074

Choquet R, Rouan L, Pradel R (2009b) Program E-SURGE: a software application for fitting multievent models. In: Thompson DL, Cooch EG, Conroy MJ (eds) Modelling demographic processes in marked populations. Springer, New York, NY, p 845-865 
Climate Prediction Center (2008a) El Niño Southern Oscillation (ENSO). Accessed 20 November 2015. www.cpc. ncep.noaa.gov/products/precip/CWlink/MJO/enso.shtml

Climate Prediction Center (2008b) North Atlantic Oscillation (NAO). Accessed 30 July 2015. www.cpc.ncep.noaa.gov/ products/precip/CWlink/pna/nao.shtml

Coll M, Shannon LJ, Moloney CL, Palomera I, Tudela S (2006) Comparing trophic flows and fishing impacts of a NW Mediterranean ecosystem with coastal upwelling systems by means of standardized models and indicators. Ecol Modell 198:53-70

Crean AJ, Marshall DJ (2009) Coping with environmental uncertainty: dynamic bet hedging as a maternal effect. Philos Trans R Soc Lond B Biol Sci 364:1087-1096

> Croxall JP, Trathan PN, Murphy EJ (2002) Environmental change and Antarctic seabird populations. Science 297: 1510-1514

- Cubaynes S, Doherty PF Jr, Schreiber EA, Gimenez O (2011) To breed or not to breed: a seabird's response to extreme climatic events. Biol Lett 7:303-306

Drent RH, Daan S (1980) The prudent parent: energetic adjustment in avian breeding. Ardea 68:225-252

> Forcada J, Trathan PN (2009) Penguin responses to climate change in the Southern Ocean. Glob Change Biol 15: 1618-1630

Frederiksen M, Furness RW, Wanless S (2007) Regional variation in the role of bottom-up and top-down processes in controlling sandeel abundance in the North Sea. Mar Ecol Prog Ser 337:279-286

Frederiksen M, Lebreton JD, Pradel R, Choquet R, Gimenez O (2014) Identifying links between vital rates and environment: a toolbox for the applied ecologist. J Appl Ecol 51:71-81

Giorgi F, Lionello P (2008) Climate change projections for the Mediterranean region. Global Planet Change 63: 90-104

Giudici A, Navarro J, Juste C, Gonzalez-Solis J (2010) Physiological ecology of breeders and sabbaticals in a pelagic seabird. J Exp Mar Biol Ecol 389:13-17

Grémillet D, Boulinier T (2009) Spatial ecology and conservation of seabirds facing global climate change: a review. Mar Ecol Prog Ser 391:121-137

> Grémillet D, Lewis S, Drapeau L, van Der Lingen CD and others (2008) Spatial match-mismatch in the Benguela upwelling zone: should we expect chlorophyll and seasurface temperature to predict marine predator distributions? J Appl Ecol 45:610-621

> Grosbois V, Gimenez O, Gaillard JM, Pradel R and others (2008) Assessing the impact of climate variation on survival in vertebrate populations. Biol Rev Camb Philos Soc 83:357-399

Halpern BS, Selkoe KA, Micheli F, Kappel CV (2007) Evaluating and ranking the vulnerability of global marine ecosystems to anthropogenic threats. Conserv Biol 21: 1301-1315

- Hamer KC (2010) The search for winners and losers in a sea of climate change. Ibis 152:3-5

$>$ Hedd A, Bertram DF, Ryder JL, Jones IL (2006) Effects of interdecadal climate variability on marine trophic interactions: rhinoceros auklets and their fish prey. Mar Ecol Prog Ser 309:263-278

Hoegh-Guldberg O, Bruno JF (2010) The impact of climate change on the world's marine ecosystems. Science 328: 1523-1528

> Jenouvrier S (2013) Impacts of climate change on avian pop- ulations. Glob Change Biol 19:2036-2057

Jenouvrier S, Barbraud C, Cazelles B, Weimerskirch H (2005a) Modelling population dynamics of seabirds: importance of the effects of climate fluctuations on breeding proportions. Oikos 108:511-522

Jenouvrier S, Barbraud C, Weimerskirch H (2005b) Longterm contrasted responses to climate of two Antarctic seabird species. Ecology 86:2889-2903

Jenouvrier S, Tavecchia G, Thibault JC, Choquet R, Bretagnolle V (2008) Recruitment processes in long-lived species with delayed maturity: estimating key demographic parameters. Oikos 117:620-628

Jenouvrier S, Péron C, Weimerskirch H (2015) Extreme climate events and individual heterogeneity shape lifehistory traits and population dynamics. Ecol Monogr 85: $605-624$

> Jiguet F, Jouventin P (1999) Individual breeding decisions and long term reproductive strategy in the king penguin Aptenodytes patagonicus. Ibis 141:428-433

Karnauskas KB, Jenouvrier S, Brown CW, Murtugudde R (2015) Strong sea surface cooling in the eastern equatorial Pacific and implications for Galápagos penguin conservation. Geophys Res Lett 42:6432-6437

Kovats RS, Valentini R, Bouwer LM, Georgopoulou E and others (2014) Europe. In: Barros VR, Field CB, Dokken DJ, Mastrandrea MD and others (eds) Climate change 2014: impacts, adaptation, and vulnerability. Part B: Regional aspects. Contribution of Working Group II to the Fifth Assessment Report of the Intergovernmental Panel on Climate Change. Cambridge University Press, Cambridge, p 1267-1326

Lafuente JG, Garcia A, Mazzola S, Quintanilla L, Delgado J, Cuttita A, Patti B (2002) Hydrographic phenomena influencing early life stages of the Sicilian Channel anchovy. Fish Oceanogr 11:31-44

- Langston NE, Rohwer S (1996) Molt-breeding tradeoffs in albatrosses: life history implications for big birds. Oikos 76:498-510

Le Bohec C, Gauthier-Lerc M, Grémillet D, Pradel R, Béchet A, Gendner JP, Le Maho Y (2007) Population dynamics in a long lived seabird: I. Impact of breeding activity on survival and breeding probability in unbanded king penguins. J Anim Ecol 76:1149-1160

Le Bohec C, Durant JM, Gauthier-Clerc M, Stenseth NC and others (2008) King penguin population threatened by Southern Ocean warming. Proc Natl Acad Sci USA 105: 2493-2497

Lebreton JD, Nichols JD, Barker RJ, Pradel R, Spendelow JA (2009) Modeling individual animal histories with multistate capture-recapture models. Advances Animal Res 41:87-173

Mante A, Debize E (2012) Mediterranean storm petrel, Hydrobates pelagicus melitensis: updated state of knowledge and conservation of the nesting populations of the Mediterranean small islands. Initiative PIM

Mariotti A, Zeng N, Lau KM (2002) Euro-Mediterranean rainfall and ENSO - a seasonally varying relationship. Geophys Res Lett 29:1621, doi: 10.1029/2001GL014248

Massetti L (2004) Identification and analysis of Mediterranean upwelling areas. MSc thesis, University of Florence

> Maxwell SM, Hazen EL, Bograd SJ, Halpern BS and others (2013) Cumulative human impacts on marine predators. Nat Commun 4:2688, doi:10.1038/ncomms3688

McClure MM, Alexander M, Borggaard D, Boughton D and others (2013) Incorporating climate science in applica- 
tions of the US Endangered Species Act for aquatic species. Conserv Biol 27:1222-1233

Mills JA, Yarrall JW, Bradford Grieve JM, Uddstrom MJ, Renwick JA, Merilä J (2008) The impact of climate fluctuation on food availability and reproductive performance of the planktivorous red billed gull Larus novaehollandiae scopulinus. J Anim Ecol 77:1129-1142

Møller AP, Fiedler W, Berthold P (2004) Birds and climate change. Advances Ecol Res 35:235-243

Møller AP, Rubolini D, Lehikoinen E (2008) Populations of migratory bird species that did not show a phenological response to climate change are declining. Proc Natl Acad Sci USA 105:16195-16200

Moreno J, Møller AP (2011) Extreme climatic events in relation to global change and their impact on life histories. Curr Zool 57:375-389

Newton I (1995) The contribution of some recent research on birds to ecological understanding. J Anim Ecol 64: 675-696

Newton I (1998) Population limitations in birds. Academic Press, London

> Nye JA, Baker MR, Bell R, Kenny A and others (2014) Ecosystem effects of the Atlantic Multidecadal Oscillation. J Mar Syst 133:103-116

Olivier F, van Franeker JA, Creuwels JCS, Woehler EJ (2005) Variations of snow petrel breeding success in relation to sea-ice extent: detecting local response to largescale processes? Polar Biol 28:687-699

Paleczny M, Hammill E, Karpouzi V, Pauly D (2015) Population trend of the world's monitored seabirds, 1950-2010. PLoS One 10:e0129342

Pardo D, Barbraud C, Authier M, Weimerskirch H (2013) Evidence for an age-dependent influence of environmental variations on a long-lived seabird's life-history traits. Ecology 94:208-220

Parmesan C (2006) Ecological and evolutionary responses to recent climate change. Annu Rev Ecol Evol Syst 37: 637-669

Parry ML, Canziani OF, Palutikof JP, van der Linden PJ, Hanson CE (2007) Climate change 2007: impacts, adaptation and vulnerability. Contribution of Working Group II to the fourth assessment report of the Intergovernmental Panel on Climate Change. Cambridge University Press, Cambridge

Péron G, Crochet PA, Choquet R, Pradel R, Lebreton JD, Gimenez O (2010) Capture-recapture models with heterogeneity to study survival senescence in the wild. Oikos 119:524-532

Pierini S, Rubino A (2001) Modeling the oceanic circulation in the area of the Strait of Sicily: the remotely forced dynamics. J Phys Oceanogr 31:1397-1412

Pilastro A, Tavecchia G, Marin G (2003) Long living and reproduction skipping in the fat doormouse. Ecology 84: 1784-1792

Pledger S, Pollock KH, Norris JL (2003) Open capturerecapture models with heterogeneity: I. Cormack-JollySeber model. Biometrics 59:786-794

> Pozo-Vázquez D, Esteban-Parra M, Rodrigo F, Castro-Diez Y (2001) The association between ENSO and winter atmospheric circulation and temperature in the North Atlantic region. J Clim 14:3408-3420

Pradel R, Hines JE, Lebreton JD, Nichols JD (1997) Capture-recapture survival models taking account of transients. Biometrics 53:60-72

Pradel R, Gimenez O, Lebreton JD (2005) Principles and interest of GOF tests for multistate capture-recapture models. Anim Biodivers Conserv 28:189-204

Pradel R, Choquet R, Lima M, Merritt J, Crespin L (2010) Estimating population growth rate from capture-recapture data in presence of capture heterogeneity. J Agric Biol Environ Stat 15:248-258

R Development Core Team (2014) R: a language and environment for statistical computing. R Foundation for Statistical Computing, Vienna

Ramírez F, Afán I, Tavecchia G, Catalán IA, Oro D, SanzAguilar A (2016) Oceanographic drivers and mistiming processes shape breeding success in a seabird. Proc R Soc B 283, doi:10.1098/rspb.2015.2287

Rayner NA, Brohan P, Parker DE, Folland CK and others (2006) Improved analyses of changes and uncertainties in sea surface temperature measured in situ since the mid-nineteenth century: the HadSST2 Dataset. J Clim 19:446-469

Reed T, Harris M, Wanless S (2015) Skipped breeding in common guillemots in a changing climate: restraint or constraint? Front Ecol Evol 3, doi:10.3389/fevo.2015. 00001

> Renault L, Oguz T, Pascual A, Vizoso G, Tintore J (2012) Surface circulation in the Alboran Sea (western Mediterranean) inferred from remotely sensed data. J Geophys Res Oceans 117:C08009, doi:10.1029/2011JC007659

> Reul A, Rodríguez V, Jiménez-Gómez F, Blanco JM and others (2005) Variability in the spatio-temporal distribution and size-structure of phytoplankton across an upwelling area in the NW-Alboran Sea, (W-Mediterranean). Cont Shelf Res 25:589-608

Ripa J, Olofsson H, Jonzén N (2010) What is bet-hedging, really? Proc R Soc B 277:1153-1154

Robert A, Chantepie S, Pavard S, Sarrazin F, Teplitsky C (2015) Actuarial senescence can increase the risk of extinction of mammal populations. Ecol Appl 25:116-124

Sanz-Aguilar A, Tavecchia G, Pradel R, Minguez E, Oro D (2008) The cost of reproduction and experience-dependent vital rates in a small petrel. Ecology 89:3195-3203

Sanz-Aguilar A, Massa B, Lo Valvo F, Oro D, Minguez E, Tavecchia G (2009) Contrasting age specific recruitment and survival at different spatial scales: a case study with the European storm petrel. Ecography 32:637-641

Sanz-Aguilar A, Tavecchia G, Minguez E, Massa B and others (2010) Recapture processes and biological inference in monitoring burrow-nesting seabirds. J Ornithol 151: 133-146

> Sanz-Aguilar A, Tavecchia G, Genovart M, Igual JM, Oro D, Rouan L, Pradel R (2011) Studying the reproductive skipping behavior in long-lived birds by adding nest inspection to individual-based data. Ecol Appl 21:555-564

Shaman J, Tziperman E (2011) An atmospheric teleconnection linking ENSO and southwestern European precipitation. J Clim 24:124-139

Shaw AK, Levin S (2013) The evolution of intermittent breeding. J Math Biol 66:685-703

Soldatini C, Albores-Barajas YV, Massa B, Gimenez O (2014) Climate driven life histories: the case of the Mediterranean storm petrel. PLoS One 9:e94526

> Solow AR, Bjorndal KA, Bolten AB (2002) Annual variation in nesting numbers of marine turtles: the effect of sea surface temperature on re-migration intervals. Ecol Lett 5:742-746

Stommel H (1963) Varieties of oceanographic experience. Science 139:572-576 
Stott I, Hodgson DJ, Townley S (2011) popdemo: provides tools for demographic modelling using projection matrices. https://cran.r-project.org/web/packages/popdemo/ index.html

Stott I, Hodgson DJ, Townley S (2012) popdemo: an R package for population demography using projection matrix analysis. Methods Ecol Evol 3:797-802

Stubben C, Milligan B, Nantel P (2012) popbio: construction and analysis of matrix population models. https://cran.rproject.org/web/packages/popbio/index.html

Sydeman WJ, Thompson SA, Kitaysky A (2012) Seabirds and climate change: roadmap for the future. Mar Ecol Prog Ser 454:107-117

Thorpe JE (1994) Reproductive strategies in Atlantic salmon, Salmo salar L. Aquacult Res 25:77-87

Tinkle DW (1962) Reproductive potential and cycles in female Crotalis atrox from northwestern Texas. Copeia 1962:306-313

Editorial responsibility: Scott Shaffer,

San Jose, California, USA
Tuljapurkar S (1993) Entropy and convergence in dynamics and demography. J Math Biol 31:253-271

Tuljapurkar S, Horvitz CC, Pascarella JB (2003) The many growth rates and elasticities of populations in random environments. Am Nat 162:489-502

Van Houtan KS, Halley JM (2011) Long-term climate forcing in loggerhead sea turtle nesting. PLoS One 6: e19043

Van Houtan KS, Halley JM, Marks W (2015) Terrestrial basking sea turtles are responding to spatio-temporal sea surface temperature patterns. Biol Lett 11: 20140744, doi:10.1098/rsbl.2014.0744

Walther GR, Post E, Convey P, Menzel A and others (2002) Ecological responses to recent climate change. Nature 416:389-395

Weimerskirch H, Inchausti P, Guinet C, Barbraud C (2003) Trends in bird and seal populations as indicators of a system shift in the Southern Ocean. Antarct Sci 15:249-256

Submitted: August 28, 2015; Accepted: April 11, 2016

Proofs received from author(s): May 30, 2016 